\title{
La audiodescripción y la accesibilidad al material cinematográfico para personas con discapacidad visual de Trujillo.
}

\author{
SILVA INFANTI, Anggy ${ }^{1}$; FLORES ARRÉSTEGUI, Analî; DURAN LLARO, Kony Luby ${ }^{3}$
}

\section{RESUMEN}

El objetivo del estudio fue determinar el impacto de la audiodescripción en la accesibilidad al material cinematográfico para personas con discapacidad visual bajo un estudio cuasi experimental con enfoque cuantitativo. Se usó como técnica la encuesta y como instrumento se aplicó un cuestionario a una muestra de 26 miembros de la Asociación Regional de Ciegos Luis Braille, obteniendo como resultado que el $87 \%$ de los participantes en la proyección de la película audiodescrita tuvieron un nivel alto de accesibilidad al material cinematográfico mientras que las personas que fueron expuestas a la película original (sin audiodescripción) obtuvieron porcentajes menores respecto a la obtención y comprensión de la información.

Palabras clave: Audiodescripción, discapacidad visual, accesibilidad, material cinematográfico

\section{Audiodescription and accessibility to film material for people with visual impairment in Trujillo}

\begin{abstract}
The aim of the study was to determine the impact of audiodescription on the accessibility of film material for people with visual impairment under a quasi-experimental study with a quantitative approach. The survey was used as a technique and a questionnaire was applied to a sample of 26 members of the Luis Braille Regional Association of the Blind, obtaining as a result that $87 \%$ of the participants in the projection of the audiodescribed film had a high level of accessibility to the cinematographic material while the people who were exposed to the original film (without audiodescription) obtained lower percentages regarding the gathering and understanding of the information.
\end{abstract}

Keywords: Audio description, visual impairment, accessibility, film material

1'Universidad César Vallejo. ORCID 0000-0002-2059-8287. anggy.silva.infante3@gmail.com

2Universidad César Vallejo. ORCID 0000-0001-6865-9109. flores.anali07@gmail.com

Universidad César Vallejo. ORCID 0000-0003-4825-3683. kony27 teacher@hotmail.com 


\section{INTRODUCCIÓN}

Durante muchos años, la inclusión social ha sido un tema muy comentado y promovido, aun pudiéndose visualizar algunas mejoras, se mantiene la inquietud si en realidad está progresando el índice de inclusión de los grupos vulnerables, especialmente de aquellos que presentan una discapacidad (McGinty, 2016). Asimismo, en este siglo el entretenimiento y la tecnología han avanzado y ahora se puede estar frente a la pantalla del celular, la televisión, la computadora o el cine obteniendo información audiovisual (Sutton, 2013) pero específicamente las personas con discapacidad visual no tienen acceso integral a esta oportunidad.

En el Perú se realizó una Encuesta Nacional especializada sobre Discapacidad y se halló que el $5.2 \%$ de peruanos presenta algún tipo de discapacidad (INEI, 2012), es decir, 1575402 personas de la población total, de los cuales 801 mil (50.9\%) presentan deficiencia visual abarcando desde la baja visión hasta la ceguera.

Por ello, la situación de este sector vulnerable en Trujillo fue motivo de reflexión para las autoras de esta investigación. Las personas con discapacidad visual de la ciudad se están esforzando por ser autosuficientes, organizándose en asociaciones y trabajando para salir adelante, y se quiso aportar con esta investigación que después también podrá servir como antecedente para futuros estudios que traten de solucionar este problema social.

Al analizar esta realidad se describieron ciertas teorías relacionadas a nuestras variables. Para ello, fue necesario definir la accesibilidad a la información, donde Pascual, Ribera y Granollers (2015) es la facilidad y flexibilidad en el uso de la información, alineándose a las necesidades y preferencias de cada usuario promoviendo el bienestar y la calidad de vida, al mejorar el entorno económico y social participativo de todos los miembros de la sociedad. Es una condición indispensable para una sociedad inclusiva. Mientras que Cebrián (2003) afirma que la accesibilidad es un término que avala el acceso integral a la información para poder ser utilizada por todos, sin ninguna restricción a todo lo que se crea o se diseña en cualquier ámbito.

Durante varios años se utilizaron distintos términos para definir la palabra discapacidad, no obstante, era importante tener en claro lo que significa dicha palabra. Enfocándonos en resultados mundiales, según estudios realizados por la Organización Mundial de la Salud (OMS, 2012), existe aproximadamente 285 millones de personas con alguna discapacidad; esto equivale a un $4 \%$ de la población mundial. Esta situación no es ajena al Perú, la Institución Nacional de Estadística e Informática (INEI, 2012) señala que un $5,2 \%$ de la población peruana presenta algún tipo de discapacidad por lo que en nuestro país se creó la Ley $\mathrm{N}^{\circ} 29973$, donde se indican ciertos criterios para velar por estas personas, teniendo como finalidad: promover la igualdad social, así como su integración en los aspectos políticos, económicos, sociales, culturales y tecnológicos; sin embargo, falta mucho para lograr el cumplimiento cabal de esta ley (Congreso de la República del Perú, 2012).

El Organismo de las Naciones Unidas (ONU, 2018) clasifica la discapacidad en 3 tipos: discapacidad física, sensorial y mental. La discapacidad física o motriz afecta el control y movimiento del cuerpo, mientras que la discapacidad sensorial se presenta en el área cerebral que controla dos tipos de sentidos: la vista y los oídos, y la discapacidad mental que afecta la comunicación y lenguaje. Para entender, tenemos que observar datos reales, por ejemplo, el $80 \%$ de la información diaria está relacionada con el órgano de la vista según Aquino, Izquierdo y García (2012). Realmente, el órgano de la vista cumple un rol importante para toda tarea.

Se describió también la accesibilidad al material audiovisual, que abarca la Televisión y Cine, donde se puede apreciar que las personas con discapacidad visual no reciben la información completa, sino que solo tienen acceso a escuchar cierta información, más no a tener detalles de lo que acontece en la pantalla; y al término de la película, se comprueba que no hubo un buen nivel de comprensión y obtención de información (García, 2015)

Esto se puede evidenciar también en el Perú, pues al asistir al cine en cualquiera de sus establecimientos, la población invidente no tiene acceso a los detalles importantes que se reflejan en la película y mucho menos comprenden lo que sucede durante los silencios.

Habiendo analizado la situación de la accesibilidad, es necesario describir los aspectos que envuelven la audiodescripción. Primero, el cine que se define como una forma de comunicación, cuya comprensión requiere la recepción de un mensaje e intención del emisor (Bustos, 2010). Se hace uso de imágenes y sonidos, de personajes e historias que siempre transmiten nociones, realidades y hasta predicciones.

La Traducción Audiovisual es una actividad que nació junto a los inicios del cine que permite 
explicar lo que se proyecta en la pantalla. Se le reconoce con mayor fuerza desde la mitad de los 90 's y desde entonces está íntimamente relacionada con el avance tecnológico. Con las inserciones que incluía el cine mudo, luego surgieron los diálogos, y se tuvo que traducir el contenido mediante subtítulos y posteriormente también a través del doblaje (Madorrán, 2016).

La subtitulación es un tipo de traducción en la que se utiliza normalmente la parte inferior de la pantalla para insertar enunciados relacionados a los diálogos como la banda sonora u otro elemento relevante escrito en alguna parte de la escena (Díaz, 2003). Acosta (2017) afirma que existen algunas consideraciones muy importantes al momento de subtitular como: el espacio entre caracteres, el tiempo de sincronización, la ortotipografía y las expresiones lingüísticas especiales. Como estándar se utilizan 37 caracteres por línea, cuidando de que cada subtítulo no esté conformado por más de dos líneas, pero que sí tengan una duración de dos a seis segundos como máximo, que se utilice las cursivas en caso de expresiones extranjeras, nombres de empresas o locuciones de televisión o radio, y logrando transmitir el mensaje contextualizado con la mayor fidelidad y transparencia.

Las voces superpuestas o voice-over es una forma de traducción en la que se incluye una voz ajena a los personajes de la transmisión. Asimismo, es importante aclarar que es diferente al doblaje ya que no reemplaza la voz original sino la mantiene en segundo plano a menos volumen como lo afirma Doane (1985, citado por Górska, 2015).

El doblaje es una técnica en la que se cambia las participaciones orales de los personajes por nuevas voces manteniendo la sincronía con el contenido visual. Es muy cotizada y ha obtenido gran demanda por el público debido al gran componente cultural y regional que se le puede agregar, formándose así una versión personalizada (Marín, 2007). En el doblaje se tiene en cuenta la sincronía kinésica que involucra la alineación de tiempo entre la expresión oral y los movimientos dentro de la escena. Asimismo, la isocronía brinda parámetros al traductor de doblaje para adecuar su traducción a las intervenciones de los personajes. Finalmente, la sincronía labial establece la naturalidad de las expresiones orales traducidas pues coinciden con la articulación de los labios de los personajes (Merino, Pajares y Santamaría, 2005)

Además, se afirma que de alguna forma siempre se ha desarrollado la audiodescripción en el entorno cercano a las personas con discapacidad visual, susurrando descripciones y comentarios sobre las imágenes que se observaban. Sin embargo, poco a poco se ha convertido en una metodología, herramienta e incluso un servicio de comunicación que promueve la accesibilidad a la información para quienes no cuentan con la capacidad de ver. (Ramos, 2013).

También la audiodescripción (AdD de aquí en adelante) se puede definir como una práctica que permite recrear las imágenes a través de una descripción oral, específicamente dirigida a personas con discapacidad visual desde el nacimiento como adquirida a lo largo del tiempo (Heredero, 2013). Se debe entender que la AdD transmite un mensaje lingüístico que proviene de contenido audiovisual, por lo que se le ubica dentro de la traducción audiovisual junto a modalidades como la subtitulación, el doblaje, entre otros (Hernández, 2015). Asimismo, es importante resaltar que la audiodescripción representa una oportunidad para quien no ve, porque a través de este servicio puede obtener información de una manera más íntegra desafiando sus impedimentos de acuerdo a AENOR (Asociación Española de Normalización y Certificación, 2005).

Para realizar esta labor se sigue una serie de pasos que incluyen: la visualización y comprensión del material, la creación del guion y su revisión, y finalmente la adaptación de la AdD al contenido audiovisual. Estos requisitos le brindan calidad y buenos resultados al producto, al momento de informar a todos, todo (Hernández, 2015).

Es por eso que es imprescindible que se analice la película seleccionada para identificar los silencios, y conocer la temática y el registro que se utilizará. Luego crear el guion usando palabras y frases concisas que logren describir oportunamente lo que la persona con discapacidad visual necesita saber para comprender el contenido sin saturarla de información. El paso siguiente será revisar y corregir el guion para que, al momento de ir al estudio de grabación, la preocupación solo sea el uso de una voz clara y neutra. Al tener esta parte lista, se procede a unir las grabaciones de voz a la película original de tal forma que el producto se perciba como uno solo (García, 2015).

Las personas con discapacidad visual podrían obtener una mejor experiencia gracias a la AdD ya que adiciona una descripción que no solo les permite comprender el mensaje de la película sino desarrollar su propia experiencia, fortaleciendo su independencia y promoviendo una mayor seguridad en ellos (Thompson, 2018).

Llegado a este punto, se estableció el problema de 
investigación ¿Qué efecto genera la Audiodescripción en la accesibilidad al material cinematográfico para personas con discapacidad visual de Trujillo? y el objetivo general fue determinar el efecto de la audiodescripción en la accesibilidad al material cinematográfico para personas con discapacidad visual y los objetivos específicos: 1) determinar el efecto de la audiodescripción en la obtención de información de las personas con discapacidad visual; 2) determinar el efecto de la audiodescripción en la comprensión de información de las personas con discapacidad visual y, 3) aplicar la audiodescripción al servicio de las personas con discapacidad visual.

Se hallaron los siguientes antecedentes que tratan problemáticas similares o iguales como: El proyecto de extensión universitaria de Aoki, Silva, Souto y Oliver (2018), quienes durante 4 años trabajaron con 22 voluntarios que presentaban discapacidad intelectual. Realizando 172 reuniones con ellos, sus familias y los empleadores de la ciudad creándose así, una red de apoyo para promover el respeto por los derechos laborales y la búsqueda de la adaptabilidad de la información para personas con discapacidad para que logren trabajar activamente.

Otra investigación muy importante es la de García (2015) que tuvo como objetivo realizar una audiodescripción de tipo profesional de una porción de la película "Relatos Salvajes" y proyectarla en la videoteca ONCE, donde participaron voluntarios con discapacidad visual, obteniéndose un resultado favorable: la comprensión total de los episodios audiodescritos, alcanzándose un nivel de comprensión equivalente al de un espectador vidente.

Por su parte, Ribeiro (2015) realizó un programa en el que se relacionan: el cine, la audiodescripción y el manejo de personas invidente, para que esta población pueda acceder a la recreación, sobre todo que tengan acceso a las películas que seleccionaron. Concluyendo que la relación entre la audiodescripción y el cine genera una influencia positiva en el aprendizaje, la accesibilidad y la inclusión de este sector vulnerable.

Mientras que Hernández (2014) tuvo como objetivo principal, la inclusión de la audiodescripción dentro del material cinematográfico tanto en el cine como en la televisión; mediante la creación de una base de datos online con audiodescripciones. Se contó con una muestra de 11 voluntarios con discapacidad visual de la ONCE, a los cuales se les aplicó un cuestionario, en donde se llegó a la conclusión que el $60 \%$ hace uso de la audiodescripción en las Apps y el $90 \%$ se sienten discriminados como público.

García, Quintana, Ruiz, Mauch, C. y Mauch, L. (2012) en su investigación tuvieron como objetivo dar a conocer la necesidad de que todos debemos tener acceso a la información y que realizar películas con audiodescripción es factible, si se siguen ciertos pasos de una guía práctica para obtener buen resultado, incrementar la accesibilidad y extenderla para que llegue a todas las personas que lo necesitan.

Para justificar el estudio se tomaron como base las teorías relacionadas a la audiodescripción y a la accesibilidad al material cinematográfico, siendo de valor teórico porque da a conocer a la audiodescripción como un tipo de traducción audiovisual que se rige en ciertos parámetros para crear un producto que mejora la accesibilidad al material cinematográfico para personas con discapacidad visual. Asimismo, es de relevancia social ya que los resultados de la investigación servirán como aporte para la Asociación Regional de Ciegos Luis Braille, uniéndonos así, a sus propios esfuerzos por tener una mejor calidad de vida promoviendo su independencia e inclusión en el área del entretenimiento.

Las hipótesis que se plantearon en esta investigación son: $\mathrm{H}_{1}$ - La audiodescripción mejora la accesibilidad al material cinematográfico para personas con discapacidad visual. $\mathrm{H}_{0}-\mathrm{La}$ audiodescripción no mejora la accesibilidad al material cinematográfico para personas con discapacidad visual. 


\section{MATERIAL Y MÉTODOS}

La población de nuestro estudio estuvo conformada de 117 miembros en la Asociación Regional de Ciegos de la Libertad Luis Braille, se consideró como muestra a 26 miembros, de los cuales, 15 participantes conformaron el grupo experimental, y 11 conformaron el grupo de control y para medir la accesibilidad al material cinematográfico se utilizó la encuesta dirigida, y se siguieron los pasos de Hernández (2015) para la elaboración de la audiodescripción. A su vez, se utilizó un cuestionario basado en el instrumento de evaluación de García (2015).

Por la presente se realizó el siguiente procedimiento:

- Se escogieron dos laboratorios de computación, uno para el grupo control y el otro para el grupo experimental. Además, se contó el apoyo de un equipo de 8 encuestadores.
- Se hizo coordinaciones para que buses recogieran a los integrantes de nuestra muestra y al llegar éstos, se hizo la división entre los 26 participantes, 11 personas conformaron el grupo control y 16 , el grupo experimental por orden de llegada.

- A ambos grupos se les aplicó un pre test, que era un cuestionario específico sobre la película que se proyectaría.

- Se proyectó la película "Mi hermano, yo y nuestra novia" (véase Anexo 2) en ambos grupos de forma paralela, en el grupo control se proyectó la película original mientras que en el grupo experimental se aplicó la película audiodescrita y se escuchó la audiodescripción a través de audífonos.

- Se aplicó el pos test, que fue el mismo cuestionario relacionado a la película.

\section{RESULTADOS}

Tabla 1. Niveles de la accesibilidad al material cinematográfico y el efecto de la audiodescripción.

\begin{tabular}{|c|c|c|c|c|c|c|c|c|}
\hline \multirow{2}{*}{ Pruebas } & \multicolumn{3}{|c|}{ Grupo control } & \multicolumn{3}{|c|}{ Grupo experimental } & \multirow{2}{*}{$\begin{array}{c}\text { Prueba } \\
\text { wilconxon }\end{array}$} & \multirow[t]{2}{*}{ Significancia } \\
\hline & Nivel & Cantidad & $\%$ & Nivel & Cantidad & $\%$ & & \\
\hline \multirow{3}{*}{ Pre test } & Alto & 0 & 0 & Alto & 0 & 0 & \multirow{3}{*}{-2.14} & \multirow{3}{*}{0.03} \\
\hline & Bajo & 11 & 100 & Bajo & 15 & 100 & & \\
\hline & Total & 11 & 100 & Total & 15 & 100 & & \\
\hline \multirow{3}{*}{ Post test } & Alto & 3 & 27 & Alto & 13 & 87 & \multirow{3}{*}{-3.57} & \multirow{3}{*}{0.00} \\
\hline & Bajo & 8 & 73 & Bajo & 2 & 13 & & \\
\hline & Total & 11 & 100 & Total & 15 & 100 & & \\
\hline
\end{tabular}

Base de datos relacionada al pre y pos test del grupo control y grupo experimental.

Figura 1. Niveles de la accesibilidad al material cinematográfico y el efecto de la audiodescripción.

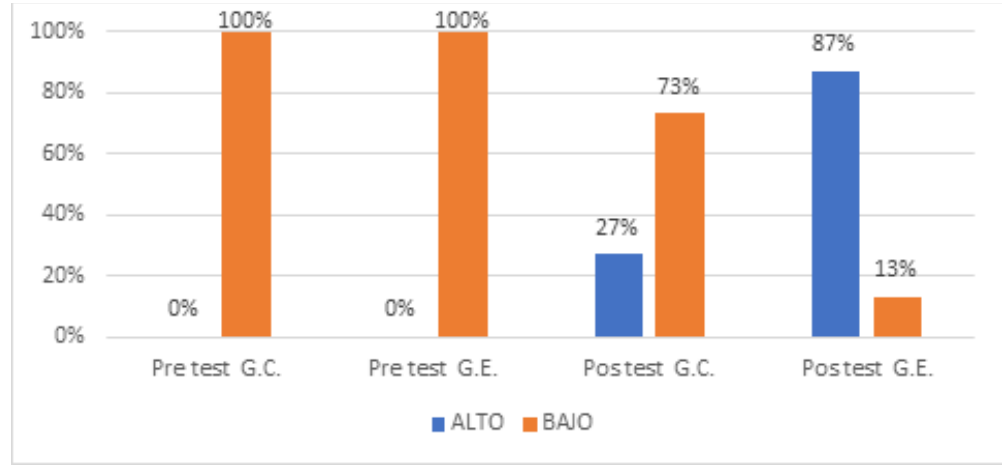

Tabla 1

Interpretación: En el Pre test, los participantes del grupo control y el grupo experimental obtuvieron un $100 \%$ de nivel bajo en sus respuestas sobre el contenido de la película. En el post test, se obtuvo una distribución diferente entre el nivel alto y el nivel bajo. 
Tabla 2. Comparación de resultados entre el pre test y pos test de los grupos control y experimental.

\begin{tabular}{|c|c|c|c|c|c|c|c|c|}
\hline \multirow{2}{*}{ Grupos } & \multicolumn{3}{|c|}{ Pre test } & \multicolumn{3}{|c|}{ Pos test } & \multirow{2}{*}{$\begin{array}{c}\text { Prue ba } \\
\text { wilconxon }\end{array}$} & \multirow{2}{*}{ Significancia } \\
\hline & Nivel & Cantidad & $\%$ & Nivel & Cantidad & $\%$ & & \\
\hline \multirow{3}{*}{ Grupo control } & Alto & 0 & 0 & Alto & 3 & 27 & \multirow{3}{*}{-1.912} & \multirow{3}{*}{0.056} \\
\hline & Bajo & 11 & 100 & Bajo & 8 & 73 & & \\
\hline & Total & 11 & 100 & Total & 11 & 100 & & \\
\hline \multirow{3}{*}{$\begin{array}{c}\text { Grupo } \\
\text { experimental }\end{array}$} & Alto & 0 & 0 & Alto & 13 & 87 & \multirow{3}{*}{-3.418} & \multirow{3}{*}{0.001} \\
\hline & Bajo & 15 & 100 & Bajo & 2 & 13 & & \\
\hline & Total & 15 & 100 & Total & 15 & 100 & & \\
\hline
\end{tabular}

Base de datos relacionada al pre y pos test del grupo control y grupo experimental.

Figura 2. Comparación de resultados entre el pre test y pos test de los grupos control y experimental.

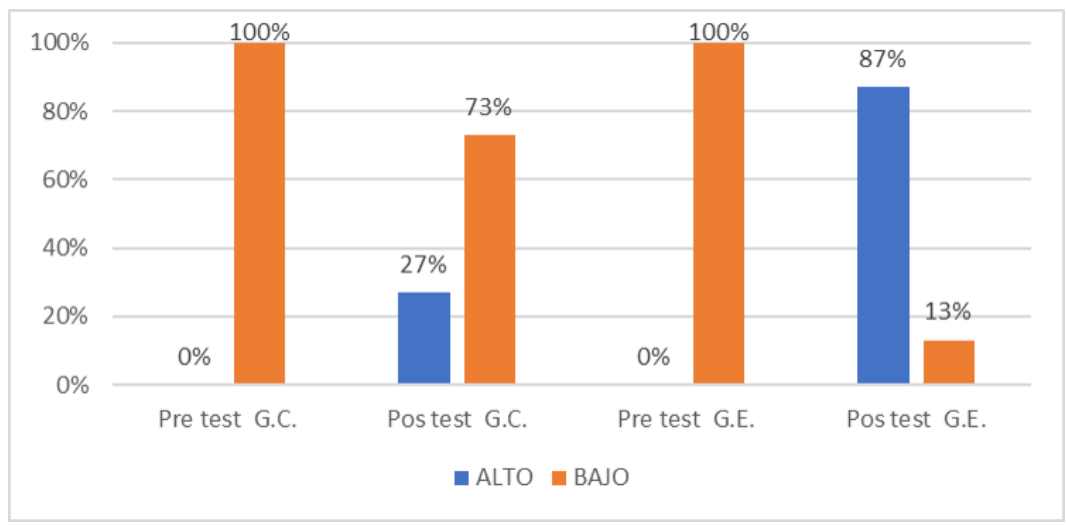

Tabla 2

Interpretación: En el grupo control, los participantes obtuvieron un $27 \%$ de nivel alto en el pos test frente a un pre test del $100 \%$ del nivel bajo con la proyección del video original. En el grupo experimental, debido a la proyección de la película audiodescrita los participantes obtuvieron un $87 \%$ de nivel alto en el pos test frente a un pre test del $100 \%$ de nivel bajo.

Tabla 3. Efecto de la audiodescripción en base a la obtención de información aplicada en el pre y pos test del grupo control y el grupo experimental.

\begin{tabular}{|c|c|c|c|c|c|c|c|c|}
\hline \multirow{2}{*}{ Grupos } & \multicolumn{6}{|c|}{ Obtención de información } & \multirow{3}{*}{ Prueba } & \multirow{3}{*}{ Significancia } \\
\hline & \multicolumn{3}{|c|}{ Pre test } & \multicolumn{3}{|c|}{ Postest } & & \\
\hline \multirow{4}{*}{ Grupo control } & Nivel & Cantidad & $\%$ & Nivel & Cantidad & $\%$ & & \\
\hline & Alto & 0 & 0 & Alto & 4 & 36 & \multirow{3}{*}{-1.357} & \multirow{3}{*}{0.175} \\
\hline & Bajo & 11 & 100 & Bajo & 7 & 64 & & \\
\hline & Total & 11 & 100 & Total & 11 & 100 & & \\
\hline \multirow{3}{*}{$\begin{array}{c}\text { Grupo } \\
\text { experimental }\end{array}$} & Alto & 0 & 0 & Alto & 13 & 87 & \multirow{3}{*}{-3.440} & \multirow{3}{*}{0.001} \\
\hline & Bajo & 15 & 100 & Bajo & 2 & 13 & & \\
\hline & Total & 15 & 100 & Total & 15 & 100 & & \\
\hline
\end{tabular}

Base de datos relacionada al pre y pos test del grupo control y grupo experimental. 
Figura 3. Efecto de la audiodescripción en base a la obtención de información aplicada en el pre y pos test del grupo control y el grupo experimental.

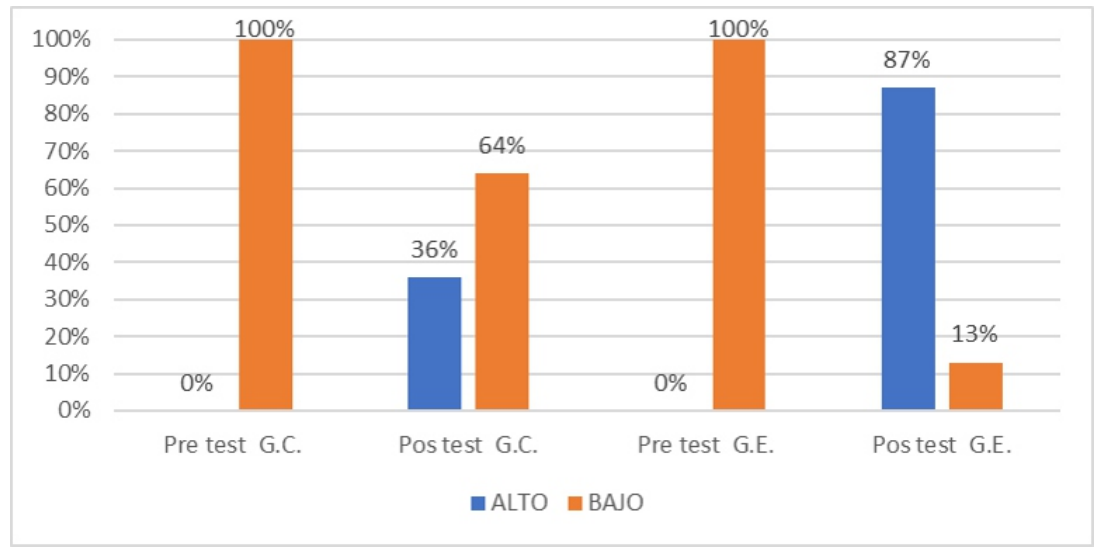

Tabla 3

Interpretación: En el grupo control, los participantes obtuvieron un 36\% de nivel alto en el pos test frente a un pre test del 100\% del nivel bajo en la obtención de información. En el grupo experimental, debido a la proyección de la película audiodescrita los participantes obtuvieron un $87 \%$ de nivel alto en el pos test en la obtención de información frente a un pre test del $100 \%$ de nivel bajo.

Tabla 4. Efecto de la audiodescripción en base a la comprensión de información aplicada en el pre y pos test en ambos grupos.

\begin{tabular}{|c|c|c|c|c|c|c|c|c|}
\hline \multirow{2}{*}{ Grupos } & \multicolumn{6}{|c|}{ Comprensión de información } & \multirow{3}{*}{ Prueba } & \multirow{3}{*}{ Significancia } \\
\hline & \multicolumn{3}{|c|}{ Pre test } & \multicolumn{3}{|c|}{ Postest } & & \\
\hline \multirow{4}{*}{ Grupo control } & Nivel & Cantidad & $\%$ & Nivel & Cantidad & $\%$ & & \\
\hline & Alto & 1 & 9 & Alto & 6 & 55 & \multirow{3}{*}{-2.332} & \multirow{3}{*}{0.020} \\
\hline & Bajo & 10 & 91 & Bajo & 5 & 45 & & \\
\hline & Total & 11 & 100 & Total & 11 & 100 & & \\
\hline \multirow{3}{*}{$\begin{array}{c}\text { Grupo } \\
\text { experimental }\end{array}$} & Alto & 4 & 27 & Alto & 13 & 87 & \multirow{3}{*}{-3.033} & \multirow{3}{*}{0.002} \\
\hline & Bajo & 11 & 73 & Bajo & 2 & 13 & & \\
\hline & Total & 15 & 100 & Total & 15 & 100 & & \\
\hline
\end{tabular}

Base de datos relacionada al pre y pos test del grupo control y grupo experimental.

Figura 4. Efecto de la audiodescripción en base a la comprensión de información aplicada en el pre y pos test del grupo control y el grupo experimental.

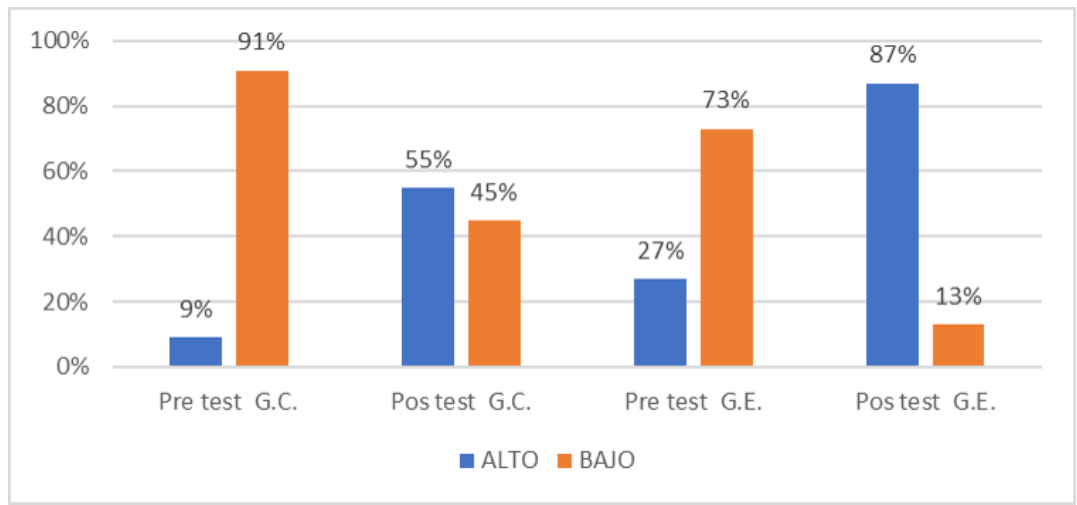

Tabla 4

Interpretación: En el grupo control, los participantes obtuvieron un 55\% de nivel alto en el pos test frente a un pre test del $91 \%$ del nivel bajo en la comprensión de información. En el grupo experimental, debido a la proyección de la película audiodescrita los participantes obtuvieron un $87 \%$ de nivel alto en el pos test en la comprensión de información frente a un pre test del 73\% de nivel bajo. 
La mayoría de las personas con discapacidad visual que obtuvieron un nivel alto de accesibilidad al material cinematográfico (87\%) fueron aquellos que estuvieron expuestos a la película audiodescrita, comprobando que este tipo de traducción audiovisual mejora la obtención y comprensión de la información para personas con discapacidad visual.

Es muy importante hacer hincapié en la importancia de tener acceso al cine porque a través de este medio de comunicación también se puede aprender. Ribeiro (2015) entendiendo esta realidad hizo un taller que verificaba que la comprensión de su población invidente incrementaba con la audiodescripción de películas, a la par en nuestro estudio podemos notar que desde la primera aplicación la comprensión de información se incrementa de gran manera generando una mayor captación de información, aprendizaje e interés en el cine.

Por lo que al igual que García (2015) nuestros resultados nos ayudan a deducir que la audiodescripción logra producir en las personas con discapacidad visual, imágenes mentales muy similares a las de una persona vidente y la creación de este tipo de descripciones remedia así, los silencios incompresibles y la falta de detalle en el hilo de la trama de una película.

Algo muy importante que promueve la audiodescripción es la mayor independencia de la persona con discapacidad visual, es por eso que Aoki et al (2018) en su investigación deja demostrado que las personas que presentan alguna discapacidad, tienen la habilidad de realizar cualquier tarea, sólo necesitan que la información se adapte a ellos. He ahí que la audiodescripción adapta el contenido audiovisual en descripciones orales para que al escucharlas sea posible la obtención de la información para quien es invidente y pueda en este caso, disfrutar de su derecho al entretenimiento.

No se puede dejar de mencionar el rol que tiene la audiodescripción en la inclusión social, ya que las películas sin audiodescripción dejan de lado a las personas con discapacidad visual destinándolas a la dependencia o a la desinformación, como se puede apreciar en los resultados de nuestro grupo control ( $73 \%$ de nivel bajo en accesibilidad), por su parte la audiodescripción logra equilibrar el avance tecnológico y el gran alcance del mundo cinematográfico logrando incluir a las personas con deficiencia visual en este rubro del entretenimiento y así evitar lo que comenta en su estudio Hernández (2014) donde la gran mayoría de sus participantes se sentían discriminados constantemente e identifican a la audiodescripción como una forma de interés positivo y deseo real de ayudar a la población invidente a tener acceso a la información.

Realizar audiodescripciones es factible y nuestro estudio y su buen resultado nos brinda esa convicción, García et al (2012) desde su posición a través de su propio estudio se une a comentario, sin embargo, ellos proponen que siempre puede realizarse un mejor producto siguiendo ciertas directivas y que el material audiodescrito debe tener el mayor alcance posible para que más personas puedan disfrutar de este servicio y oportunidad. Las muestras pequeñas son muy importantes y van sumándose a más proyectos de diferentes países concientizando a las naciones de la necesidad de incluir la audiodescripción junto al subtitulado y doblaje al servicio de las personas que lo necesiten.

\section{CONCLUSIÓN}

1) El $87 \%$ de los participantes en el grupo experimental obtuvieron un nivel alto de accesibilidad al material cinematográfico a causa de la audiodescripción, evidenciando el gran aporte que este tipo de traducción audiovisual genera en las personas con discapacidad visual contribuyendo al aprendizaje y a la inclusión social en nuestro país.

2) Se aduce que el $73 \%$ de la muestra que participó en el grupo experimental obtuvo un nivel alto en obtención de información debido a la película audiodescrita. Este resultado refleja cómo el grupo experimental logró captar gran cantidad de las intervenciones audiodescritas por ende, obtener información accesible.

3) Debido al material audiodescrito, el $73 \%$ de los participantes en el grupo experimental obtuvieron un nivel alto en la comprensión de información contenida en las intervenciones audiodescritas de la película. Esto quiere decir que mediante este tipo de traducción se genera un nivel de comprensión igual o similar al de un espectador vidente llegando a ser una herramienta clave para las personas con discapacidad visual. 


\section{REFERENCIAS BIBLIOGRÁFICAS}

Acosta, L. (2017). Normas de subtitulación: conocimientos que pueden valer un empleo en Netflix. Revista digital INESEM . Recuperado de: https://revistadigital.inesem.es/idiomas /normas-subtitulacion/

AENOR (2005): Norma UNE 153020. Audiodescripción para personas con discapacidad visual. Requisitos para la audiodescripción y elaboración de audioguías, Madrid, AENOR.

Aoki, M., Silva, R., Souto, C., y Oliver, F. (2018). People with Disabilities and the Development of Community Strategies To Promote Participation in the Labor Market. Revista Brasileira de Educação Especial, 24(4), 517-534. https://dx.doi.org/10.1590/s141365382418000500004

Aquino, S., Izquierdo, J. y García, V. (2012). La inclusión educativa de ciegos y baja visión en el nivel superior. Un estudio de c a so. Re c u p e rado de: http://www.scielo.org.mx/scielo.php?scr ipt $=\mathrm{sci}$ arttext\&pid=S1665$109 \times 2012000200007$

Bastos, J., Duquia, R., González D., Mesa, J. y Bonamigo, R. (2014). Field work I: selecting the instrument for data collection. Anais Brasileiros de Dermatologia, 89(6), 918-923. R e c u p e r a d o d e : http://www.scielo.br/scielo.php?pid=S03 $6505962014000600918 \&$ script $=$ sci artte xt\&tlng $=e s$

Bustos, P. (2010). El Cine como herramienta eficaz para un aprendizaje concreto, activo y reflexivo: una experiencia en Aula. Congreso Iberoamericano de Educación METAS 2021. Buenos Aires, Argentina. R e c u p e r a d o d e : http://www.adeepra.org.ar/congresos/Co ngreso\%20IBEROAMERICANO/EDUCARTI STICA/RLE3324 Bustos.pdf

Cebrián, M. (2003). Glosario de discapacidad visual. Madrid: ANORMI, S.L

Congreso de la República del Perú (2012). Ley general de la persona con discapacidad $\mathrm{N} \circ 29973$. Re cuperado de: https://www.mimp.gob.pe/webs/mimp/he rramientas-recursos-violencia/contenedor-

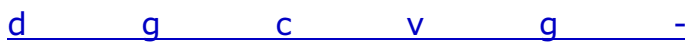
recursos/contenidos/Legislacion/Leygeneral-de-la-Persona-con-Discapacidad29973.pdf

Díaz J. (2003). Nuevos retos y desarrollos en el mundo de la subtitulación. Puentes N.0 6, noviembre 2005, págs. 13-20

Disman, Mohammad, A. y Syaom, B. (2017). The use of Quantitive Research Method and Statistical Data Analysis in Dissertation: An Evaluation Study. International Journal of Education. Recuperado de: https://www.researchgate.net/publication /319468820 THE USE OF QUANTITATIV E_RESEARCH_METHOD_AND_STATISTICA L DATA ANALYSIS IN DISSERTATION A N_EVALUATION_STUDY

Florindo, A y Latorre, M. (2003). Validation and reliability of the Baecke questionnaire for the evaluation of habitual physical activity in adult men. Revista Brasileira de Medicina do Esporte, 9(3), 129-135. Recuperado de: http://www.scielo.br/scielo.php?pid=S151 7-86922003000300002\&script=sci arttext

Fullerton, T. y Barraza de Anda, M. (2008). Borderplex Population Modeling. Migraciones internacionales, 4(3), 91-104. R e c u p e ra d o d e : http://www.scielo.org.mx/scielo.php?script $=\mathrm{sci}$ arttext\&pid=S 1665 $\underline{89062008000100005}$

García A., Quintana I., Ruiz B., Mauch C. y Mauch L. (2012). El cine para todos como vehículo de aprendizaje. Madrid: Centro Español de Documentación sobre Discapacidad.

García, I. (2015) La audiodescripción para ciegos de "Relatos Salvajes" Revista Científica sobre Accesibilidad Universal La Ciudad Accesible vol.7 (5): 105-120

Górska K. (2015). Ni doblaje ni subtitulación. El gran éxito del Voice-Over en la televisión polaca. Quaderns, 10 (2015), pp. 63-72

Heredero A. (2013). Audiodescripción: Acceso a la cultura. Revista Nebrija de Lingüística Aplicada 13 (número especial - Actas de Congreso).

Hernández M. (2015). Audiodescripción: traducción y accesibilidad a los contenidos audiovisuales. Recuperado de: 
https://riuma.uma.es/xmlui/handle/1063 $\underline{0 / 10485}$

INEI (2012). Primera encuesta nacional especializada sobre discapacidad. R e c u p e ra d o d e http://www.conadisperu.gob.pe/estadisti cas-en-discapacidad

Kjellström S., Ross S. y Fridlund, B. (2010). Research ethics in dissertations: Ethical issues and complexity of reasoning. Journal of medical ethics. 36. 425-30. R e c u p e ra d o d e : 10.1136/jme.2009.034561.

Madorrán C. (2016). Traducción Audiovisual: análisis prácticos del guión audiodescrito de la película de animación La edad de hielo: el deshielo (Carlos Saldanha, 2006). (Trabajo de fin de grado, Universidad de Valladolid, Soria, España). Recuperado de: http://uvadoc.uva.es/handle/10324/1880 3? mode $=$ full

Manterola, C. y Otzen, T. (2015).Experimental Studies 2nd Part: Quasi-experimental Studies. International Journal of Morphology, 33(1), 382-387. Recuperado de:https://scielo.conicyt.cl/scielo.php?pid $=\begin{array}{lllll}\mathrm{S} & 0 & 7 & 1 & 7\end{array}$ $95022015000100060 \&$ script $=$ sci arttext $\&$ tllng=en

Marín C. (2007). Traducción para el doblaje de películas multilingües: Babel. (Tesina de maestría, Universidad de las Palmas de Gran Canaria, España). Recuperado de:https://acceda.ulpgc.es/xmlui/bitstrea $\mathrm{m} / 10553 / 4064 / 1 / 0536366000000000$. pdf

Martinez, González, Duquia, Bonamigo y Bastos (2016). Sampling: how to select participants in my research study? Anais Brasileiros de Dermatologia, 91(3), 326330 . R e c u p e r a d o d e : http://www.scielo.br/scielo.php?pid=S035 $-05962016000300326 \&$ script $=$ sci_arttext

McGinty J. (2016). Accessibility and inclusion in Higher Education: An inquiry of faculty perceptions ad experiences (Tesis de doctorado, Colorado State University, Estados Unidos). Recuperado de:https://mountainscholar.org/bitstream hhandle/10217/176779/McGinty colostat e_0053A_13824.pdf?sequence $=1$

Merino R., Pajares E. y Santamaría J. (2005). Trasvases culturales: Literatura, cine y traducción 4. España: Universidad del País
Vasco.

OMS (2012). Clasificación según los tipos de discapacidades. Recuperado de https://www.um.es/discatif/METODOLOGI A/Egea-Sarabia clasificaciones.pdf

ONU (2018). Definición y aclaración de la palabra discapacidad y personas con habilidades diferentes. Convención sobre los derechos de las personas con discapacidad. R e c u p e ra d o d e : https://www.who.int/es/news-room/factsheets/detail/disability-and-health

Pascual, A., Ribera, M., y Granollers, T. (2015). Impact of web accessibility barriers on users with a hearing impairment. Dyna, 82 (193), 233-240. Recuperado de: http://www.redalyc.org/pdf/496/4964214 1029.pdf

Phiton, M. (2013). Importance of the control group in scientific research. Dental Press Journal of Orthodontics, 18(6), 13-14. R e c u p e r a d o d e : http://www.scielo.br/scielo.php?script=sci arttext\&pid $=$ S2176-94512013000600003

Ramos M. (2013). El impacto emocional de la audiodescripción. (Tesis doctoral, Universidad de Murcia, España). R e c u p e rad o d e : https://www.tesisenred.net/handle/10803 $\angle 124169$

Ribeiro I. (2015). A parte invisível do olhar: audiodescrição no cinema: a constituição das imagens por meio das palavras - uma possibilidade de educação visual para a pessoa com deficiência visual no cinema. (Tesis de maestría, Universidad Estatal de Campinas, Sao Paulo, Brasil). Recuperado d http://repositorio.unicamp.br/jspui/handle /REPOSIP/285178

Sutton B. (2013). The Effects of Technology in society and Education. Education and Human Development Master's Theses. 192. R e c u p e rad o de : https://digitalcommons.brockport.edu/eh d theses/192/?utm source $=$ digitalcommo ns.brockport.edu\%2Fehd theses $\% 2$ F 192 \&utm_medium =PDF\&utm_campaign =PDF CoverPages

Thompson H. (2018). Audio Description: Turning Access to film into cinema Art. Disability Studies Quarterly, 38 (3), DOI: $10.18061 /$ dsq.v38i3.6487 